\title{
Nachruf auf Horst Becke
}

Horst Becke ist im Alter von 89 Jahren von uns gegangen.

Er war ein bedeutender Vorreiter und Lehrer der Naturheilkunde, der Akupunktur, der Neuraltherapie, der Medizin!

Seine medizinische Laufbahn begann mit dem Studium der Medizin in München an der Ludwig-Maximilian-Universität München, 1954 bestand er das Staatsexamen mit der Note „sehr gut“ und promovierte im gleichen Jahr mit der Note „Magna cum laude“.

Nach kurzem Intermezzo in Vilshofen in Niederbayern ging es an die Medizinische Akademie in Erfurt bis 1957. Im Kreiskrankenhaus Mühlhausen wurde er dann zum Facharzt für Gynäkologie und Geburtshilfe ausgebildet und wurde 1959 dort Oberarzt. 1961 bekam er dann die Leitung der Frauenklinik in Ludwigsfelde angeboten. 1988 gab er die Leitung der Frauenklinik ab und gründete am Krankenhaus Ludwigsfelde eine stationäre Abteilung für Schmerz- und Regulationstherapie sowie eine Schmerzambulanz. Eine solche Institution war in der gesamten DDR einmalig. Diese führte er bis 1995 . Bis 2015 blieb er seinen Patienten in einer privaten Praxis erhalten.

1956 begann seine Begeisterung für die Neuraltherapie nach einem Seminar bei Huneke in Freudenstadt. Er bildete sich weiter fort und begann bald zu unterrichten.

1971 wurde dann die „Arbeitsgruppe Neuraltherapie in der Gesellschaft für Klinische Medizin der DDR“ gegründet, deren Leiter er war.

Die Akupunkteure waren schon direkt dabei, es durfte aber der Begriff Akupunktur nicht verwendet werden, es hieß dann „Nadelung“.

Der Oberbegriff war immer die „Reflextherapeutisch-regulativen Behandlungsmethoden".

Ab 1978 entwickelte er die curriculare Ausbildung in Akupunktur und Neural-

Deutsche Zeitschrift für Akupunktur 2019 • 62 (3): 229

https://doi.org/10.1007/s42212-019-0203-7

Online publiziert: 22. Juli 2019

(c) Springer Medizin Verlag $\mathrm{GmbH}$, ein Teil von

Springer Nature 2019 therapie immer weiter, so entstanden die ersten Ausbildungsprogramme unserer Gesellschaft.

1986/1987 absolvierte er dann eine Ausbildung in Chirotherapie.

1988 erfolgte dann die Ernennung zum Medizinalrat.

Horst Becke schrieb eine B-Promotion an der Akademie für Ärztliche Fortbildung Berlin zum Thema „Neuraltherapie bei Kreuzschmerz und Migräne“. Es war die erste fundierte wissenschaftliche Arbeit, die die Wirkmechanismen zusammenfasst und die Effektivität der Neuraltherapie statistisch belegt. Damit habilitierte er 1991 zum Dr. sc. med.

1991 erfolgte auch Ernennung zum Ehrenmitglied der DÄGfA und zum 100. Geburtstag von Ferdinand Huneke erhielt er den Voss-Laurenz Preis der IGNH.

Am 21. Januar 1997 verlieh Bundespräsident Prof. Dr. Roman Herzog ihm das Verdienstkreuz am Bande der Bundesrepublik Deutschland.

Nach der Wende wurde dann am 30.03.1990 die DGfAN gegründet und Horst Becke zum Präsidenten gewählt. Dieses Amt behielt er bis April 1999 inne.

Seit 2001 war Horst der erste Ehrenpräsident der DGfAN und erhielt 2008 die Ehrenmedaille der DGfAN.

Nachdem er seine Frau schwer erkrankt war, hat Horst Becke sich mehr und mehr zurückgezogen, um sie zu pflegen. Als sie vor 2 Jahren verstorben war, hat er sich seiner zweiten Familie, der DGfAN wieder mehr gewidmet und war dann vor 2 Jahren bei unserer Mitgliederversammlung in Erfurt dabei. Bei dieser Versammlung wurde ich dann zu seinem Nach-Nachfolger gewählt. Wir alle, die neu in den Vorstand kamen hatten für uns das Bild entwickelt, dass wir auf den Schultern von Riesen stehen und dadurch erst einen guten Blick in die Zukunft werfen können. Horst war für uns wie der Mount Evererst, der Berg auf dem unsere Vorgänger, die Riesen stehen konnten. Er hat uns in diese gute Position gebracht, in der die DGfAN sich heute befindet. Dafür gebührt ihm unser ewiger Dank!

Bei unserer Dozentenschulung 2017 kam Horst $\mathrm{zu}$ mir und machte mir ein großes Kompliment. Nach dieser Schu-
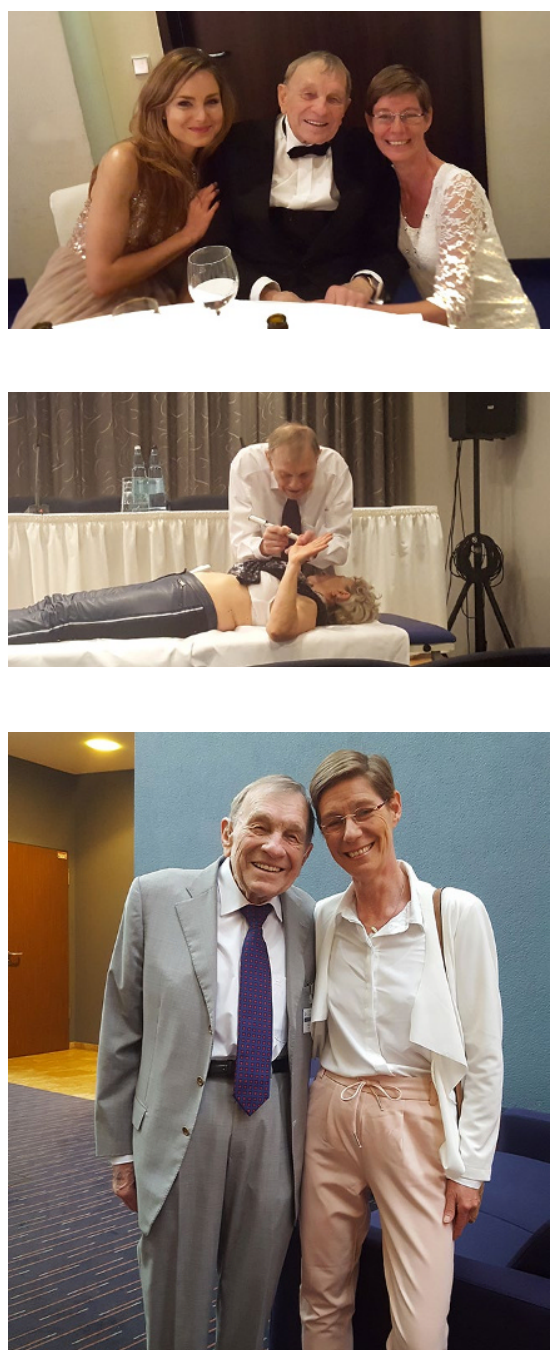

lung sagte er, sei er bereit zu sterben, denn er wisse seine DGfAN Familie in guten Händen.

Und dann kam die Flamme wieder ans brennen - er wollte wieder in die Manege. Mit seiner „Ziehtochter" Cordula Christoph fing er wieder an zu unterrichten und beim diesjährigen Kongress in Erfurt hielt er 2 Workshops ab! Die Resonanz war riesengroß, die Teilnehmer begeistert.

Unser Verlust ist kaum in Worte zu fassen. Unser Andenken wird Horst Becke in Ehren halten und unser Mitgefühl gilt seiner wundervollen Familie mit 5 Kindern, 10 Enkeln und 2 Urenkeln.

\section{Dr. med. Siddhartha Popat}

Präsident der DGfAN 